\title{
Kinetic Studies on Oxidative Dissolution of Elemental Mercury in Aqueous Sodium Hypochlorite
}

\author{
S. Bandyopadhyay, S. Chakraborty, D. B. Zaini, and S. Bhattacharjee
}

\begin{abstract}
Aqueous sodium hypochlorite is often used to detoxify solid wastes containing elemental mercury and its compounds by oxidative dissolution of mercury in the form of a soluble mercurochloro complex. Experiments were conducted to estimate global kinetics and interfacial mass transfer parameters of the reaction between elemental mercury and aqueous sodium hypochlorite. The reaction did not conform to either pure mass transfer or pure instantaneous reaction regimes. The order and activation energy of the reaction were estimated to be 1.168 and $13.48 \mathrm{~kJ} \mathrm{~mol}^{-1}$ respectively. Experimental data on reaction enhancement factors may be used for design of an industrial solid waste detoxification reactor.
\end{abstract}

Index Terms-Mercury, solid waste, sodium hypochlorite.

\section{INTRODUCTION}

Elemental mercury and its compounds are highly toxic to the environment. Vast amount of research data dealing with decontamination of gaseous emissions and liquid streams containing trace quantities of elemental mercury and its compounds are now available [1]-[3]. Some of these technologies are now well developed and involve dissolution of mercury vapour in aqueous hypochlorite solution [4], [5] or adsorption onto various conventional and novel adsorbents [6], [7].

Scanty information on basic kinetics of the mercury-hypochlorite reaction is available. Nene and Rane [8] studied the absorption of mercury in aqueous solution of $\mathrm{HOCl}, \mathrm{HOCl}$ and $\mathrm{NaCl}, \mathrm{NaOCl}, \mathrm{NaOCl}$ and $\mathrm{NaCl}, \mathrm{KOCl}$ and $\mathrm{KOCl}$ and $\mathrm{KCl}$ at $303 \mathrm{~K}$ in a disc column and reported the pseudo-first order rate constants for these systems. Zhao and Rochelle [9] carried out an extensive study on absorption of mercury vapor in different reagents. They determined the kinetics of reaction between mercury vapor and potassium permanganate in a well-characterized gas-liquid contactor. They also measured the rate of absorption of elemental mercury vapor into aqueous hypochlorite in a stirred tank reactor at $298 \mathrm{~K}$ and $308 \mathrm{~K}$. $\mathrm{NaOCl}$ strongly absorbed mercury even at high $\mathrm{pH}$. Low $\mathrm{pH}$, high chloride concentration and high temperature favor mercury absorption. Aqueous free chlorine was the active species that reacted with

Manuscript was received June 18, 2015; revised August 26, 2015. This research was sponsored by the grant FRGS (1/2014/TK05/UTP/02/5) from the Ministry of Higher Education (MOHE), Malaysia.

S. Bandyopadhyay is with the University of Mississippi Medical Center (UMMC) in Jackson, MS, USA.

S. Chakrabarti is with the Department of Chemical Engineering, University of Calcutta, India.

D. B. Zaini and S. Bhattacharjee are with Chemical Engineering Department, Universiti Teknologi PETRONAS, Malaysia (e-mail: sekhar.bhatta@petronas.com.my). mercury and second order reaction kinetics was observed between elemental mercury and free chlorine.

Solid wastes are often treated with aqueous sodium hypochlorite to remove mercury and its compounds. Brine mud of a chlor-alkali industry containing elemental mercury and its salts is a solid waste and is usually dumped off-site in a lined pond. Sometimes this brine mud is treated with aqueous sodium hypochlorite to remove toxic mercury from the sludge. This is a solid-liquid reaction and involves mass transfer of mercury from the solid matrix into a liquid phase. Sizeneva $e t$ al. [10] studied oxidative dissolution of $\mathrm{Hg}^{0}$ in $\mathrm{NaOCl}$ at $\mathrm{pH}$ 5.9, 6.5, 6.9 and 8.5 at $25^{\circ} \mathrm{C}$ and $50^{\circ} \mathrm{C}$. It was observed that the first order rate was maximum in the $\mathrm{pH}$ range of $6.5-6.9$. The dissolution process was reported to be heterogeneous involving simultaneous chemical reaction and diffusion. Aqueous phase oxidation of gaseous elemental mercury by potassium persulphate and catalyzed by $\mathrm{Ag}^{+}$has been studied by Ye et al. [11] in a glass bubble column reactor where tertiery-butyl-alcohol (TBA) was used as a free radical scavenger. Effects of $\mathrm{pH}$, concentration of potassium persulphate and silver nitrate, temperature, reactor-inlet concentration of $\mathrm{Hg}^{0}$ and TBA were studied. Increase in initial concentration of potassium persulphate and silver nitrate increased the rate of oxidation whereas increase in temperature and TBA-concentration showed negative effect. Neutral $\mathrm{pH}$ was observed to facilitate oxidation. About $60 \%$ of the original $\mathrm{Hg}^{0}$ present was removed within 210 minutes. Pala and Ariya [12] reported their experimental findings on kinetics of $\mathrm{O}_{3}$-initiated oxidation reaction of $\mathrm{Hg}^{0}$ over a temperature range of $283-323 \mathrm{~K}$ and at or near atmospheric pressure. The pseudo-first order rate constant was reported. The reaction product was identified as $\mathrm{HgO}$ from the suspended aerosol.

In order to analyze the oxidative dissolution process of $\mathrm{Hg}^{0}$ in aqueous sodium hypochlorite and arrive at a meaningful mathematical result, data on mass transfer parameters and reaction rates are necessary. In the present paper results on mass transfer and global kinetics of reaction between elemental mercury and sodium hypochlorite are reported.

\section{EXPERIMENTAL PROCEDURES}

A $250 \mathrm{~mL}$ glass beaker of $6.5 \mathrm{~cm}$ diameter was employed as a stirred cell and a four blade turbine agitator of $2 \mathrm{~cm}$ diameter was used for stirring the aqueous phase. The beaker was placed in a constant temperature bath $( \pm 1 \mathrm{~K})$ for maintaining constant temperature during the experiment. A temperature probe and a $\mathrm{pH}$ probe were used for continuous digital monitoring of the temperature and $\mathrm{pH}$ of aqueous medium. $150 \mathrm{~g}$ of elemental mercury was taken in the beaker 
and sodium hypochlorite of various concentrations and volumes were added for each set of experiments. $10 \mathrm{~mL}$ of dilute $1 \mathrm{M}$ hydrochloric acid was added initially to the reaction mixture to dissolve insoluble mercury (II) oxide formed by the reaction between elemental mercury and sodium hypochlorite.

A set of experiments was designed to study the global kinetic parameters and transfer mechanism of elemental mercury across interface to the aqueous sodium hypochlorite solution. Concentration of sodium hypochlorite, $\mathrm{pH}$, temperature, volume of the reaction mixture, specific surface area and speed of agitation of the aqueous phase were varied. Experiments were conducted at the following conditions: $\mathrm{CNaOCl}(0): 0.0292-0.1157 \mathrm{~mol}^{-\mathrm{dm}^{-3}}$; T: $300 \mathrm{~K}-328 \mathrm{~K}$; $\mathrm{pH}: 1-9 ; \mathrm{V}: 60 \mathrm{~mL}-195 \mathrm{~mL} ; \mathrm{a}: 20.75-54.14 \mathrm{~m}^{2} / \mathrm{m}^{3} ; \mathrm{C}_{\mathrm{HCl}}$ : $1 \mathrm{~mol} . \mathrm{dm}^{-3}$; r: $100-600 \mathrm{rpm} .4 \mathrm{~mL}$ aliquot was drawn out from the reaction mixture at 10 minute intervals for estimation of concentrations of sodium hypochlorite [13] and total mercury [14]. AAS absorbance versus mercury concentration plot showed excellent linearity (Range: $4.98 \times 10^{-5}-9.95 \times 10^{-4}$ mol.dm $\left.{ }^{-3} ; \mathrm{R}^{2}=0.996\right)$ with zero intercept.

\section{RESULT AND DISCUSSION}

Sodium hypochlorite reacts with elemental mercury to form mercury (II) oxide which is insoluble in the aqueous phase. Presence of hydrochloric acid in the reaction mixture dissolves the $\mathrm{Hg}$ (II) oxide formed. These two reactions (1 and 2) and overall reaction (3) can be shown as follows [15]

$$
\begin{gathered}
\mathrm{Hg}+\mathrm{NaOCl} \rightleftharpoons \mathrm{HgO}+\mathrm{NaCl} \\
\mathrm{HgO}+2 \mathrm{HCl} \rightleftharpoons \mathrm{HgCl}_{2}+\mathrm{H}_{2} \mathrm{O} \\
\mathrm{Hg}+\mathrm{NaOCl}+2 \mathrm{HCl} \rightleftharpoons \mathrm{HgCl}_{2}+\mathrm{NaCl}+\mathrm{H}_{2} \mathrm{O}
\end{gathered}
$$

To study the thermal degradation kinetics of $\mathrm{NaOCl}, 150$ $\mathrm{mL}$ solutions of sodium hypochlorite of concentration 0.0583 mol.dm-3 was taken in a $250 \mathrm{~mL}$ beaker and placed in a constant temperature bath. The reaction mixture was stirred continuously. $\mathrm{pH}$ and temperature of the solution were monitored throughout the experiment. The reaction was monitored for 60 minutes and between temperatures $303 \mathrm{~K}$ $328 \mathrm{~K} .2 \mathrm{~mL}$ aliquots were drawn out from the reaction vessel at 10 minute intervals to estimate the concentration of sodium hypochlorite iodometrically. Sodium hypochlorite underwent marginal thermal degradation - in 60 minutes concentration of sodium hypochlorite decreased by less than $1.83 \pm 0.23 \%$ of its initial value (experimental data not shown here). Other reported investigations [10], [15] confirm the fact that sodium hypochlorite disproportionates only at temperatures higher than $353 \mathrm{~K}$. Therefore, in experiments, where reaction temperature was varied between $300 \mathrm{~K}$ and $328 \mathrm{~K}$, loss of concentration of sodium hypochlorite by thermal degradation was considered insignificant and neglected.

Experiments were performed with fixed and known initial concentrations sodium hypochlorite $-0.0293,0.0583,0.0875$ and $0.1157 \mathrm{~mol} . \mathrm{dm}^{-3}$. Two typical plots showing time-concentration profiles of $\mathrm{Hg}^{2+}$ and $\mathrm{NaOCl}$ in the reaction medium are shown in Fig. 1 and Fig. 2. Assuming that the elemental mercury phase is pure and uncontaminated, the rate equation for reaction 3 may be expressed with a power law kinetic equation given below:

$$
r=\frac{d\left[\mathrm{Hg}^{2+}\right]}{d t}=k[\mathrm{NaOCl}]^{n}
$$

where $r$ is the rate of dissolution of elemental mercury into the reaction medium and $\mathrm{k}$ is the apparent rate constant. The rate versus $\mathrm{C}_{\mathrm{NaOCl}}$ plot ( $t=0-60$ minutes) is shown in Fig. 3 . The plot is linear and data for concentration-time plot for four different initial concentrations of $\mathrm{NaOCl}$ fell on a single line $\left(R^{2}=0.8587\right)$. From the slope of this line, global order of reaction 3 with respect to sodium hypochlorite $(n)$ was estimated to be equal to $1.168\left(r^{2}=0.859\right)$.

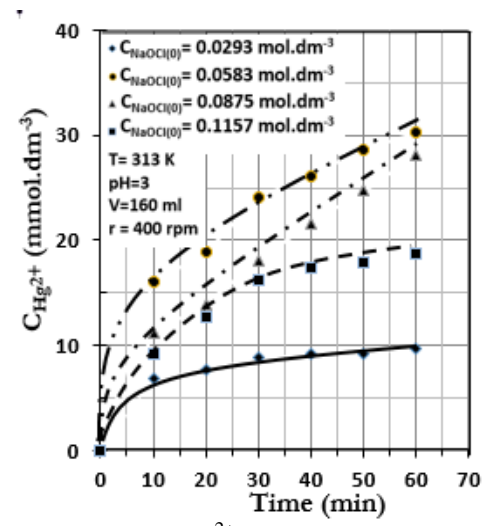

Fig. 1. Concentration of $\mathrm{Hg}^{2+}$ versus time profile (reaction 3).

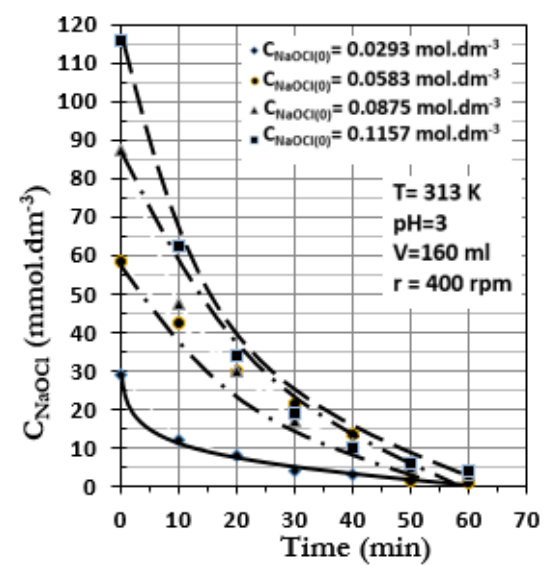

Fig. 2. Concentration of $\mathrm{NaOCl}$ versus time profile (reaction 3).

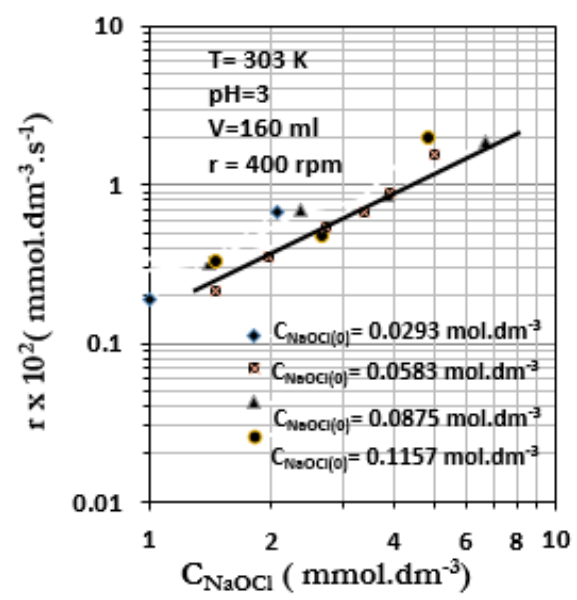

Fig. 3. Rate versus sodium hypochlorite concentration profile (reaction 3). 
Reactions between elemental mercury and sodium hypochlorite in presence of hydrochloric acid were carried out at different temperatures $-300 \mathrm{~K}, 313 \mathrm{~K}, 320 \mathrm{~K}$ and 328 $\mathrm{K}$ in a constant temperature bath. The rate data were plotted against $\mathrm{NaOCl}$ concentration for each set of experiment (Fig. 4). These plots are nearly parallel to each other indicating that the order of the reaction and hence, the mechanisms of mass transport of elemental mercury across the interface and subsequent reaction in the aqueous medium remain unaltered with change in reaction temperature.

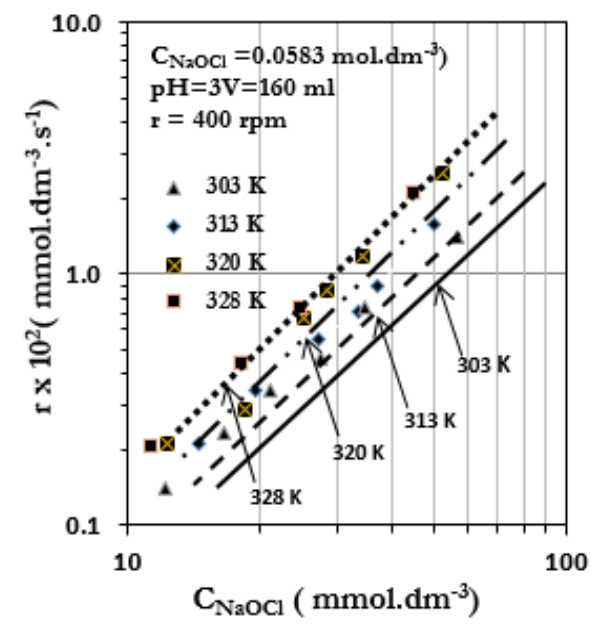

Fig. 4. Rate versus sodium hypochlorite concentration profile (reaction 3) at different temperature.

From the slope, values of rate constant (equation 3) at each temperature was calculated. From an Arrhenius plot of rate constant data, pre-exponential factor $\left(A=1.29 \times 10^{-2} \mathrm{~mol}\right.$. $\left.\mathrm{dm}^{-3} \cdot \mathrm{s}^{-1}\right)$ and activation energy $\left(E=13.48 \mathrm{~kJ} \mathrm{~mol}^{-1}\right)$ were calculated. The global kinetics of the oxidative dissolution of elemental mercury in sodium hypochlorite can be represented by equation 5 . Low value of activation energy (between 5 and $20 \mathrm{~kJ} / \mathrm{mol}$ ) is indicative of significant mass transfer resistance at the phase boundary.

$$
r=\frac{d\left[\mathrm{Hg}^{2+}\right]}{d t}=k[\mathrm{NaOCl}]^{n}=1.29 \times 10^{-2} e^{-\left(\frac{13484.74}{R T}\right)}[\mathrm{NaOCl}]^{1.168}
$$

The $\mathrm{pH}$ of pure sodium hypochlorite in the concentration range $\left(0.02917\right.$ to $\left.0.1157 \mathrm{~mol} . \mathrm{dm}^{-3}\right)$ of our study has a $\mathrm{pH}$ between 11.60 to 12.56 . During the progress of the reaction at baseline condition or when other parameters were varied (except for the experiments where effect of $\mathrm{pH}$ of the medium was investigated) the $\mathrm{pH}$ of the reaction medium was maintained at 3 by dropwise addition of $1 \mathrm{~mol} . \mathrm{dm}^{-3}$ of $\mathrm{HCl}$ to the reaction medium. pHs of different sets of experiments were maintained at $1,3,7$ and 9 respectively by adding different volumes of $\sim 1 \mathrm{M}$ hydrochloric acid to the reaction mixture. Total volume of hydrochloric acid added to keep the $\mathrm{pH}$ constant was less than $10 \mathrm{~mL}$. The initial rate of reaction was very high at $\mathrm{pH} 1$ but declined considerably at $\mathrm{pH} \mathrm{3,} 7$ and 9. At low $\mathrm{pH}$ insoluble mercury (II) oxide formed by reaction of elemental mercury with sodium hypochlorite dissolved instantaneously in the reaction medium and hence the initial rate was very high. With the progress of the reaction as concentration of sodium hypochlorite in the reaction mixture dropped, the rate fell. At higher $\mathrm{pH}$, dissolution of mercury (II) oxide by hydrochloric acid was slower thus adversely affecting the global kinetics.

Experiments were carried out at 100, 200, 400 and $600 \mathrm{rpm}$ to investigate the effect of speed of agitation on heterogeneous $(\mathrm{L}-\mathrm{L})$ reaction between elemental mercury and sodium hypochlorite in presence of hydrochloric acid (the reaction was monitored for 60 minutes). From an analysis of experimental data it is inferred that speed of agitation has marginal effect on the global kinetics. For a liquid-liquid heterogeneous reaction the observation suggests that the rate of mass transfer of elemental mercury across the liquid-liquid interface is not rate limiting.

To further investigate the role of on interfacial mass transfer on reactive dissolution process, $20 \mathrm{~mL}$ of elemental mercury was taken in a $500 \mathrm{~mL}$ beaker immersed in a constant temperature bath and to this $200 \mathrm{~mL}$ of triple distilled water was added without creating any mechanical disturbance in the liquid mercury. Immediately a turbine impeller made of glass connected with a variable speed motor was immersed in water as close to the interface as possible and rotated at a definite speed. Mass balance equation for transport of elemental mercury into the aqueous phase can be written as

$$
V \frac{d A}{d t}=k_{l} a\left(A^{*}-A\right)
$$

while the integrated form of transport equation is

$$
\ln \frac{A^{*}}{\left(A^{*}-A\right)}=k_{l}\left(\frac{a}{V}\right) t
$$

Alekhin et al. [16] reported elemental mercury solubility of $2.96 \times 10^{-6} \mathrm{~mol}^{-\mathrm{dm}^{-3}}$ in water at $300 \mathrm{~K}$. From the slope of a linear plot between $\ln \left[A^{*} /\left(A^{*}-A\right]\right.$ vs. $\mathrm{t}$ data mass transfer coefficient values were calculated. Mass transfer coefficient values were found to increase linearly till about $200 \mathrm{rpm}$. After $200 \mathrm{rpm}$, the curve reached an asymptotic value of about $3.96 \times 10^{-5} \mathrm{~m} \mathrm{~s}^{-1}$. As the speed of agitation during the reactive dissolution process was maintained at $400 \mathrm{rpm}$ the rate of reaction between elemental mercury and $\mathrm{NaOCl}$ showed marginal dependence on speed of agitation.

Interfacial transport of mercury to the liquid-liquid interface may be important during reaction between elemental mercury and sodium hypochlorite. Interestingly, no product of mercury gets extracted into the mercury phase- so mercury is always pure and there is no mass transfer resistance in the mercury phase. This suggests that the initial reaction occurs at the interface and the liquid-liquid film on the aqueous phase side does not play any role at all. As the reaction proceeds, hypochlorite concentration gradually decreases and that perhaps reduces rate of supply of hypochlorite to the interface.

\section{CONCLUSION}

Detailed experimental studies were carried out to investigate the roles of global kinetics and interfacial mass 
transfer during oxidative dissolution of elemental mercury in aqueous sodium hypochlorite. The reaction occurs at the liquid-liquid interface during the initial period of reaction, gradually the reaction shifts to a regime that is very close to instantaneous. The global order of the reaction is close to unity suggesting that the reaction can be suitably modeled by pseudo-first order kinetics for design of an industrial reactor.

\section{NOMENCLATURE}

$a=$ interfacial area $\left(\mathrm{m}^{-1}\right)$

$A=$ Concentration of elemental mercury (mol.dm ${ }^{-3}$ )

$A^{*}=$ solubility of elemental mercury in water $\left(\mathrm{mol} . \mathrm{dm}^{-3}\right)$

$C_{\mathrm{NaOCL}(0)}=$ initial molar concentration of sodium hypochlorite $\mathrm{t}=0\left(\mathrm{~mol} \cdot \mathrm{dm}^{-3}\right)$

$C_{\mathrm{NaOCl}}=$ concentration of sodium hypochlorite in the solution at any time $\mathrm{t}\left(\mathrm{mol} . \mathrm{dm}^{-3}\right)$

$C_{\mathrm{HCl}}=$ concentration of hydrochloric acid added (mol. $\left.\mathrm{dm}^{-3}\right)$

$C_{\mathrm{Hg} 2+}=$ concentration of $\mathrm{Hg}^{2}+$ in the solution at any time $\mathrm{t}$ $\left(\right.$ mol.dm ${ }^{-3}$ )

$E=$ activation energy for reaction (3) $\left(\mathrm{kJ}^{\mathrm{m}} \mathrm{\textrm {mol } ^ { - 1 }}\right)$

$k=$ rate constant for reaction $(3)\left(\mathrm{min}^{-1}\right)$

$k_{\mathrm{L}}=$ mass transfer coefficient $\left(\mathrm{m} \cdot \mathrm{s}^{-1}\right)$

$r=$ speed of agitation (rpm)

$n=$ order of reaction

$T=$ temperature $(\mathrm{K})$

$t=$ time $(\mathrm{min})$

$V=$ volume of reactor $\left(\mathrm{dm}^{3}\right)$

\section{REFERENCES}

[1] C. Yan et al., "Evaluation of mercury speciation and removal through air pollution control devices of a $190 \mathrm{MW}$ boiler," J. Env. Sci, vol. 22 , no. 2, pp. 277-282, 2010.

[2] P. H. John, L. H. Lucinda, and Z. Ye, "Mercury control technologies for coal combustion and gasification systems," Fuel, vol. 89, no. 4, pp. 838-847, 2010.

[3] Z. Yuanjing, J. D. Anker, W, Christian, and J. Flemming, "Review of technologies for mercury removal from flue gas from cement production processes," Prog. Energy \& Combust Sci, vol. 38, no. 5, pp. 599-629, 2012

[4] C. Viktor, B. Bernie, F. Istvan, and G. Gilbert, "Kinetics and mechanism of catalytic decomposition and oxidation of chlorine dioxide by hypochlorite ion," Inorg. Chem, vol. 40, no. 8, pp. 1833-1836, 2001.

[5] R. S. Mahwar, "Mercury loss abatement in a chlor-alkali plant: II Management of brine house wastes," Chem. Age of India, vol. 37, pp. 843-850, 1986

[6] Y. Hongqun, X. Zhenghe, F. Maohong, E. B. Alan, and J. R. Roddie., "Adsorbents for capturing mercury in coal-fired boiler flue gas," J. Haz Mat, vol. 146, no. 1-2, pp. 1-11, 2007.

[7] C. Ji, S. Boxiong, L. Zhuo, C. Jianhong, and H. Chuan, "Removal of elemental mercury by clays impregnated with $\mathrm{KI}$ and $\mathrm{KBr}$," Chem. Eng. $J$, vol. 241, pp. 19-27, 2014.

[8] S. Nene and V. C. Rane, "Kinetics of the absorption of mercury," Indian J. Technol, vol. 19, no. 1, pp. 20-25, 1981.

[9] Z. L. Lynn and R. T. Gary, "Mercury absorption in aqueous hypochlorite," Chem. Engg. Sc, vol. 54, no. 5, pp. 655-662, 1999.
[10] I. P. Sizeneva, V. A. Val'tsifer, and V. N. Strelnikov, "A study of mercury dissolution in aqueous solutions of sodium hypochlorite," Russian J. of Applied Chem, vol. 78, no. 4, pp. 546-548, 2005.

[11] Y. Qun-feng, W. Cheng-yun, W. Da-hui, S. Guan, and X. Xin-hua, "Hg0 absorption in potassium persulphate solution," J. of the Zhejiang University Science B, vol. 7, no. 5, pp. 404-410, 2006.

[12] P. Biswajit and A. A. Parisa, "Studies of ozone initiated reactions of gaseous mercury: kinetics, product studies, and atmospheric implications," Chem. Phys., vol. 6, pp. 572-579, 2004.

[13] G. H. Jeffery, J. Bassett, J. Mendham, and R. C. Denny, Vogel's Quantitative Chemical Analysis, 5th ed., New York: Addison Wesley Longman Inc, 1989.

[14] M. Lucotte, R. Schetagne, N. Therien, C. Langlois, and A. Tremblay, Mercury in the Biogeochemical Cycle: Natural Environments and Hydroelectric Reservoirs of Northern Quebec, Springer Science \& Business Media, 1999, ch. 2, pp. 41-43.

[15] J. Lee, Concise Inorganic Chemistry, London: ELBS, 1996, ch. 28, pp. 844-846.

[16] Y. V. Alekhin, N. R. Zagrtdenov, and R. V. Mukhamadiyarova, " $\mathrm{Hg} 0$ (liq)- $\mathrm{Hg} 0$ (solution) equilibrium and solubility of elementary mercury in water," Moscow Univ. Geol. Bull, vol. 66, no. 6, pp. 439-441, 2012.

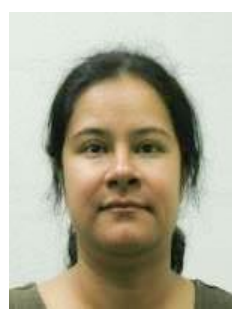

S. Bandyopadhyay received her M.Sc.in chemistry from University of Calcutta and later worked as a research fellow on detoxification of hazardous solid wastes containing mercury. After completion of her $\mathrm{PhD}$ at University of Georgia, she worked as a postdoctoral research fellow at the Georgia Institute of Technology. She is currently working as a scientist a the University of Mississippi Medical Center (UMMC) in Jackson, MS, USA.

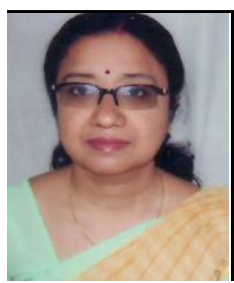

S. Chakrabarti earned her B.Tech, M.Tech and $\mathrm{Ph} . \mathrm{D}$ degrees in chemical engineering from the University of Calcutta. She was a visiting scientist in the field of nanoparticle synthesis at the University at Buffalo (SUNY) in 2012. At present she is supervising four Ph.D. students as an associate professor in the Department of Chemical Engineering, University of Calcutta, India.

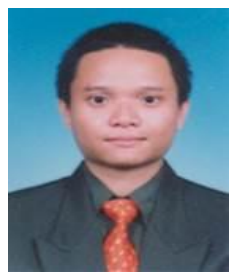

D. B. Zaini is a senior lecturer in Chemical Engineering Department of UTP. His expertise is in the area of inherent safety and risk analysis. He also has experienced in QRA consultancy works for chemical process industries. $\mathrm{He}$ is an associate member of IChemE UK and the student advisor for IChemE UTP.

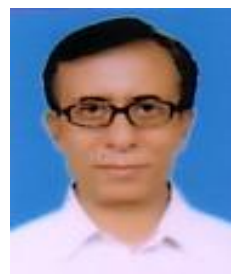

S. Bhattacharjee received his B.Tech from Calcutta University, M.Tech from Indian Institute of Technology, India and Ph.D. from University of Pittsburgh, U.S.A. Before joining Universiti Teknologi PETRONAS, he was associated with the University of Calcutta, India and as a visiting professor at the University of Alberta, Canada. His present research interests are in kinetic and morphological studies on gold nanoparticles conjugated with biomolecules, flavonoids and phytochemicals. 